\title{
NEW EXTRA-LARGE 350-MM-THICK X 2.6-METER-WIDE SLAB CASTER AT YINGKOU*
}

\author{
Stefano Baf ${ }^{1}$ \\ Giovanna Busolin ${ }^{2}$
}

\begin{abstract}
This paper describes the main technical and process solutions applied to the extrathick and wide slab caster built at Yingkou (Liaoning, P.R. of China), as well as all the features required to achieve the surface and internal quality targets.

Keywords: Very thick slab casting; Hard cooling profile; Soft cooling profile; Bgrades; Dynamic soft reduction; Q-Pulse system; Mould design; FEM analysis for SEN; Thick plates.
\end{abstract}




\section{INTRODUCTION}

Yingkou's caster is designed to produce 350-mm-thick slabs up to $2600 \mathrm{~m}$ in width with excellent quality. It is also capable of casting $250-\mathrm{mm}$ and $300-\mathrm{m}$ thick slabs of good quality. This means widely varying casting speeds ranging from a minimum of $0.4 \mathrm{~m} / \mathrm{min}$ to a maximum of $1.6 \mathrm{~m} / \mathrm{min}$, and high flexibility as well. The typical product of this slab caster are slabs feeding two plate mills, one for medium and the other for thick plates. All the steel grades cast can be considered "crack-sensitive". This aspect has been taken into account starting from the choice of a roll diagram having an 11-meter radius in order to keep strain as low as possible, and utilizing all the latest solutions in all caster areas.

Table 1: Main caster data

\begin{tabular}{|c|c|c|c|}
\hline Yearly Capacity & 1.6 Mtpy & \multicolumn{2}{|c|}{ Product details } \\
\hline Heat size & 120 ton & Thickness & $250-300-350 \mathrm{~mm}$ \\
\hline Main radius & $11 \mathrm{~m}$ & Width & $1600-2600 \mathrm{~mm}$ \\
\hline Vertical Length & $2.45 \mathrm{~m}$ & & \\
\hline Metallurgical Containment Length & $37.1 \mathrm{~m}$ & & \\
\hline
\end{tabular}

Commissioning started with the $350-\mathrm{mm}$ to meet the market demand of that period. Due to low demand, during the first phase of commissioning the caster was unable to demonstrate its full capability. When market demand increased the caster started to produce in long sequences with several "flying tundish" changes, thus showing its capability with virtually no interruption.

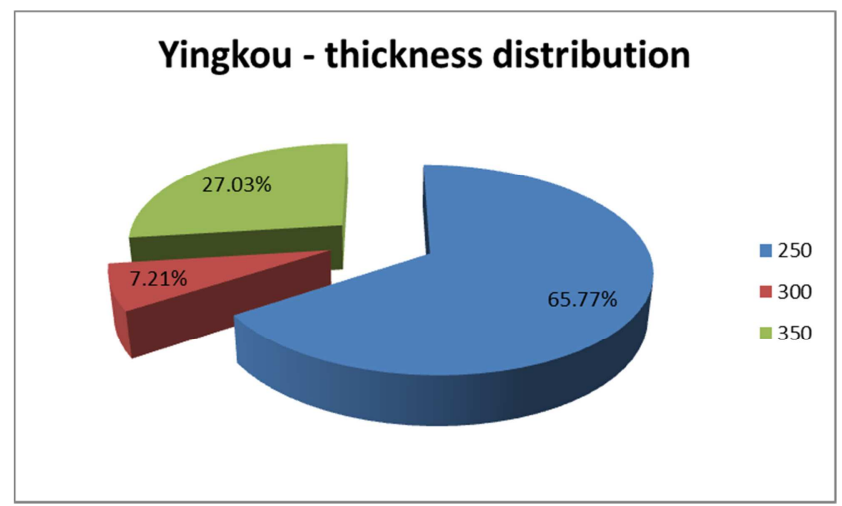

Figure 1 : Thickness distribution

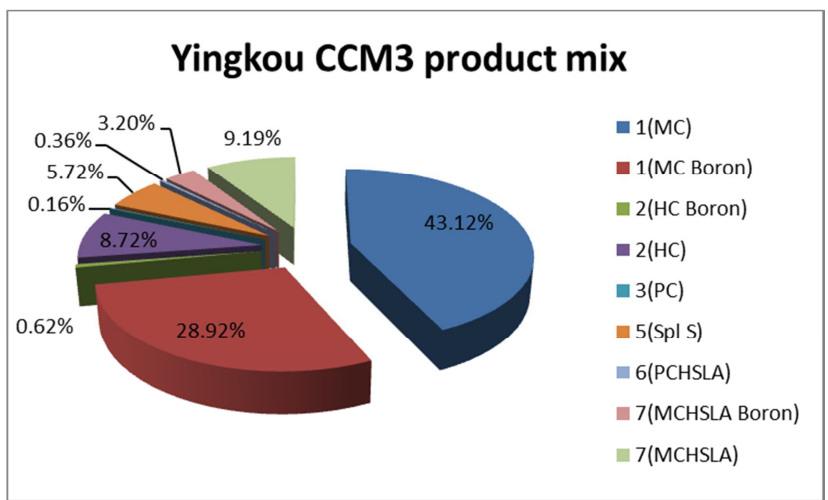

Figure 2: Typical product mix 


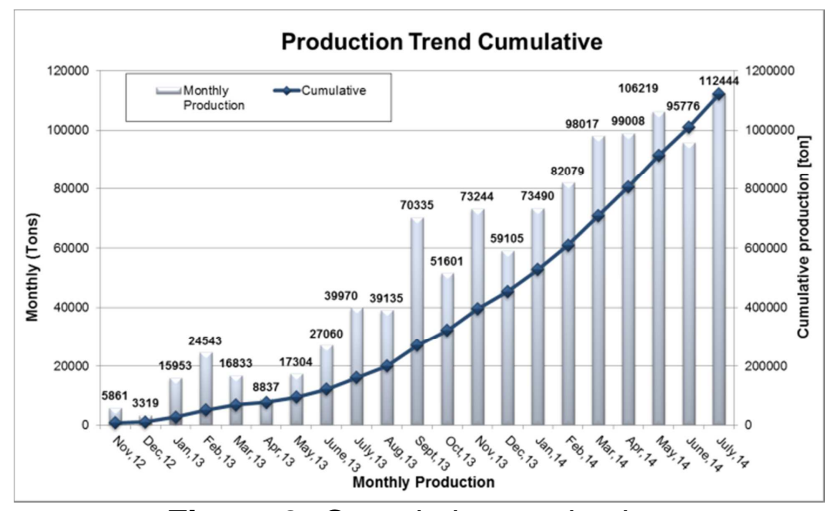

Figure 3: Cumulative production

\section{EQUIPMENT}

\subsection{Mould Area}

\subsubsection{Surface quality}

As previously mentioned, all steel grades cast are considered "crack-sensitive". The first aspect that has to be taken into account in order to ensure good surface quality is mould behavior. The following section describes all the design and process features necessary to minimize caster surface defects.

\subsection{Mould Design}

Uniform heat transfer in the mould is key to avoiding longitudinal crack formation. Furthermore, even temperature distribution on the copper plate will also improve its durability due to lower thermal stress. For this reason, in the design of the copper plates an initial design was used and then optimized using extensive FEM thermomechanical simulation. The pictures below compare the initial design to the final optimized one.

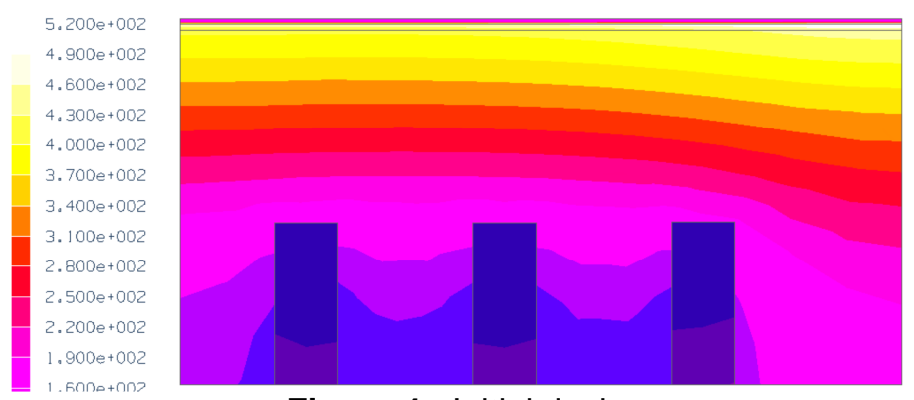

Figure 4 : Initial design

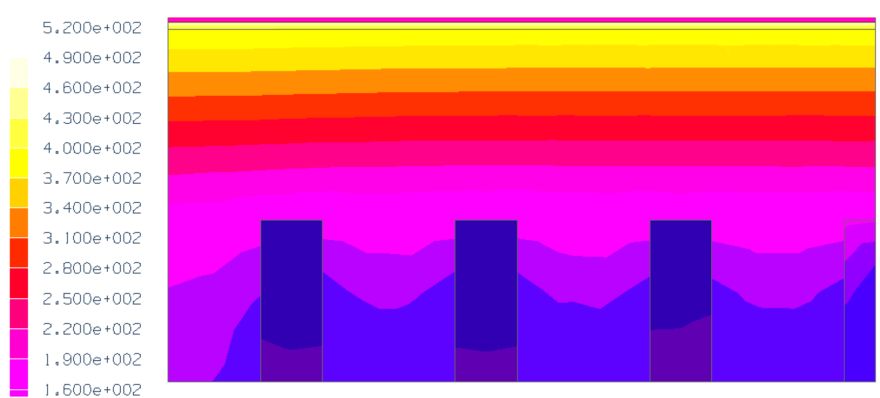

Figure 5: Optimized design 


\subsection{Oscillator}

Good surface quality is also linked to the shape of oscillation marks. A precondition to obtain regular marks is mould precision guidance by means of an oscillator, while their depth can be controlled with dedicated oscillation parameters. In the Yingkou caster this is done by Q-INMO+, a fully hydraulic oscillator capable of producing any oscillation pattern with high-precision guidance. After six months of operation, performance was checked with accelerometers and, as can be seen in the picture below, the left-right and front-rear displacements were found to be far below $0.1 \mathrm{~mm}$, meaning practically no deviation in oscillator movement.

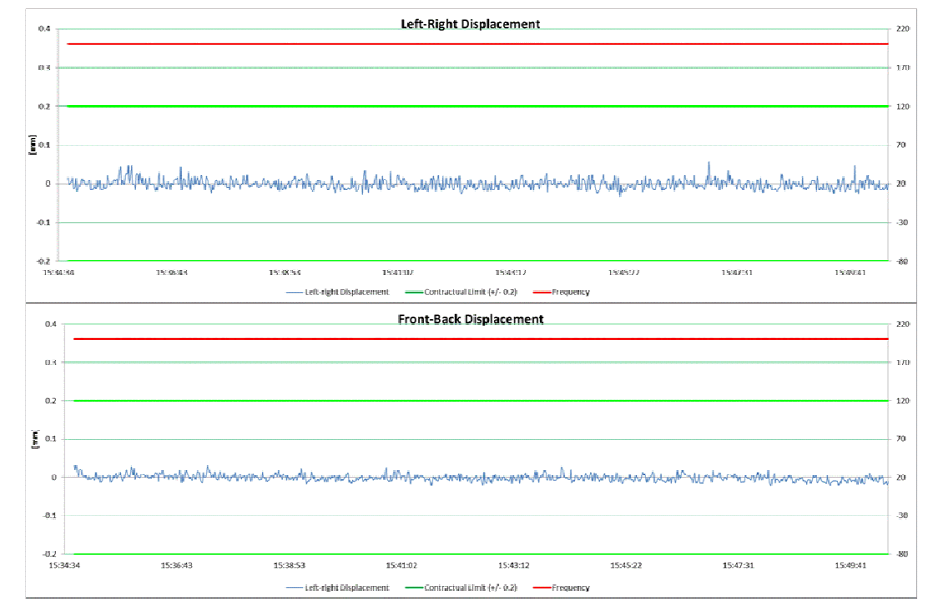

Figure 6: Oscillator displacement after six months of operation

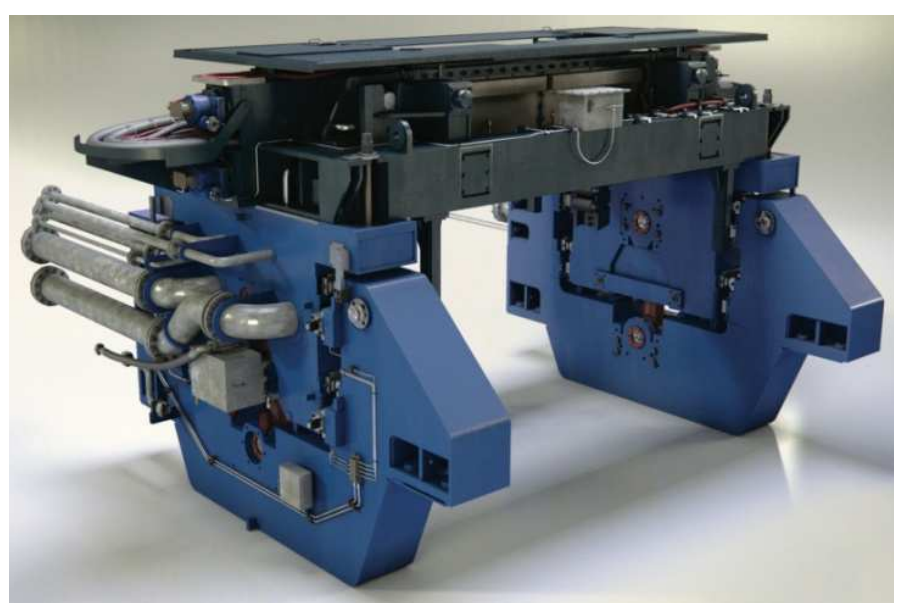

Figure 7: Fully hydraulic oscillator Q-INMO+

\subsection{Mould Fluid Dynamics}

Flow pattern in the mould is another parameter that strongly influences surface quality. Various caster defects are related to particular mould conditions [1]. Too strong a flow to the meniscus with a high span (the height of the "wave") can lead to powder entrapment, or lack of powder infiltration. A weak flow can create an undesired "single-roll" pattern, or too low a temperature in the meniscus, which can in turn cause powder melting and entrapment problems.

For the above-mentioned reasons, SEN design was first verified by CFD studies to ensure that average fluctuations in meniscus velocity were in the proper range. An example of how this method is applied is the verification done to the original SEN 


\section{6th}

design when, for market reasons, the caster had to operate in range of productivity lower than the design one. Studies showed that the original large-port SEN was not providing enough flow to the meniscus, so after examining a smaller port design, the second one had been chosen. Figures 9 and 10 show the comparison. Although numerical simulations can provide many details they need to be validated by measurements taken during real casting conditions. To evaluate the real velocity field and the meniscus span in different casting conditions a thin plate and "nail dipping" were applied [2]. Results confirmed the existence of the expected "double-roll" flow and a sub-meniscus velocity field consistent with numerical simulations. (Figure 11)

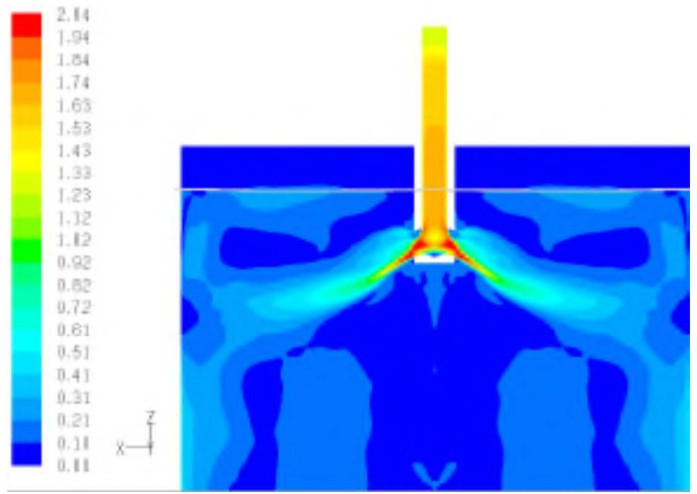

Figure 8: Flow pattern from CFD simulation (velocity contours) for smaller port SEN design

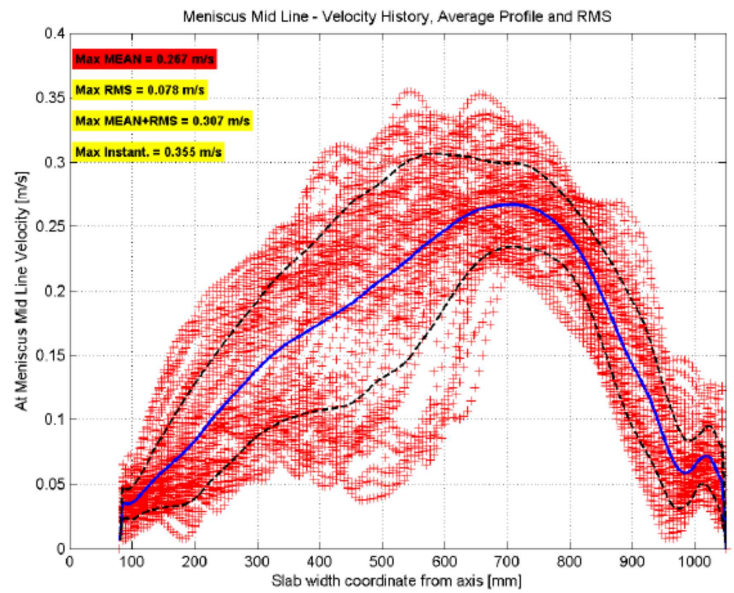

Figure 9: Meniscus mid-line velocity SEN with smaller ports

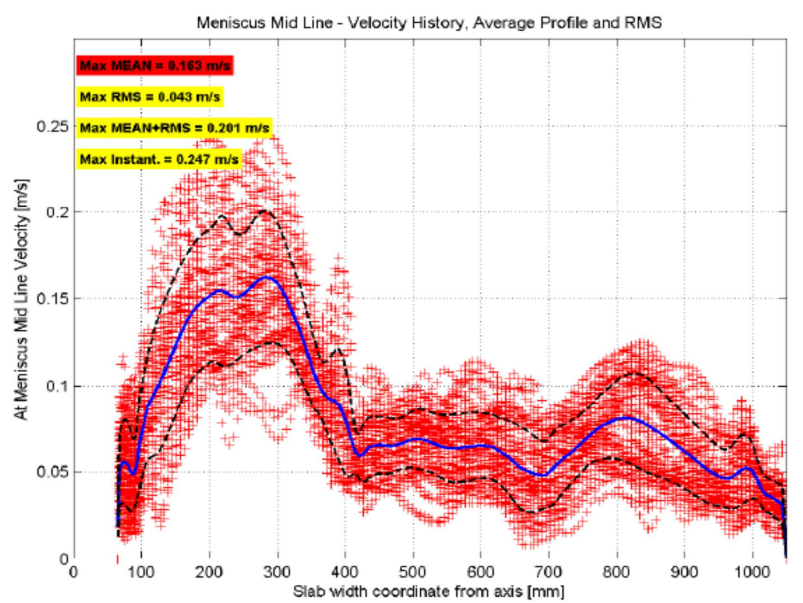

Figure 10: Meniscus mid-line velocity SEN with larger ports 
FIXED $\begin{array}{lllllllll}100 & 200 & 300 & 400 & 500 & 600 & 700 & 800 & 900\end{array}$
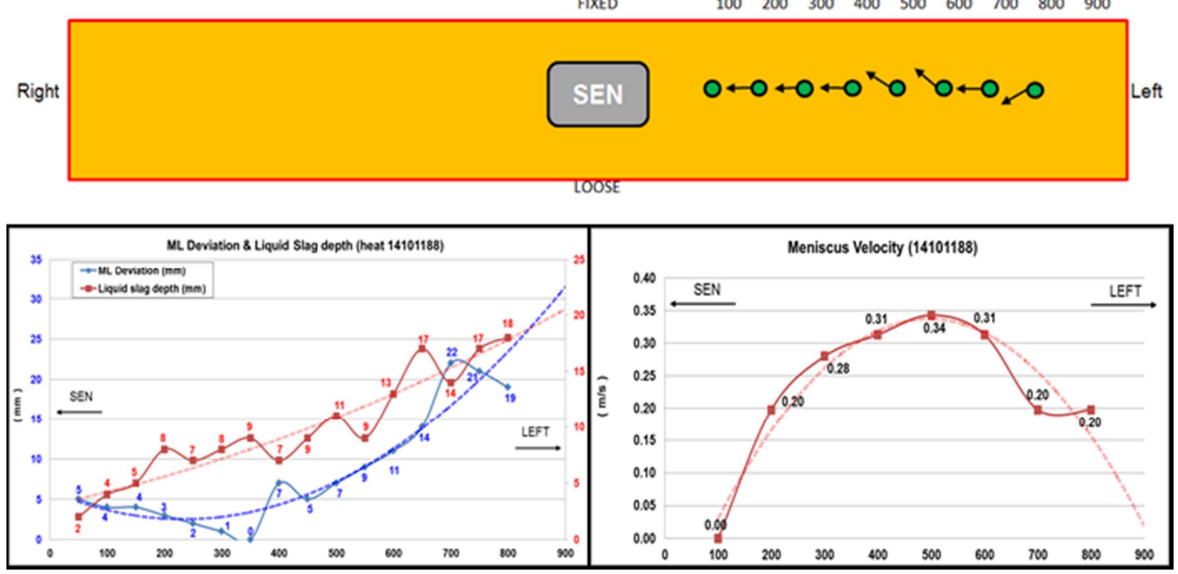

Figure 11: Nail dipping method results

\subsection{Mould Level Control}

Mould level stability has a strong influence on oscillation mark depth and powder infiltration.

The Yingkou caster is equipped with an eddy current mould level system and an advanced technological package of mould level control. One of its main features is the algorithm that counteracts periodic disturbances such as bulging, standing waves, roll eccentricity. Although dynamic bulging is a typical problem of high casting speed it may also appear when casting some alloyed grades at lower speeds.

This system has been tuned and successfully applied and figure [11] shows its effectiveness.

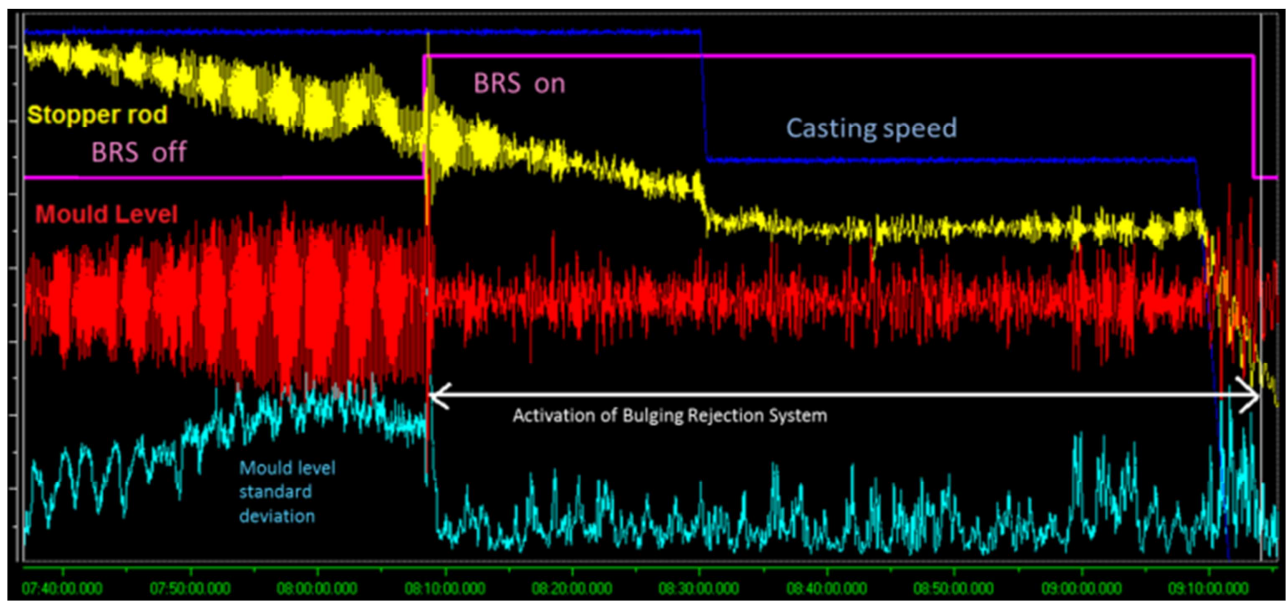

Figure 12: Example of activation of Bulging Rejection System

\subsection{Secondary Cooling}

Transverse corner cracks are a typical problem of plate grades [3][4]. Such defects appear in the notch of oscillation marks, indicating that the origin can be traced back to the mould, hence the importance given to all mould-related aspects. What is typical of these grades is that they present a strong reduction in ductility within a certain temperature range [5], roughly from $750{ }^{\circ} \mathrm{C}$ to $950^{\circ} \mathrm{C}$. The combination of mechanical stresses and the loss in ductility give rise to defects. The control of surface temperature across the width in the bending and unbending area is the most effective way of counteracting transverse corner cracks. The Yingkou caster is 
provided with a secondary cooling system where each zone up to the straightening area is split into three widths. Each of these zones has a separate flow control, in order to have different water densities across the slab width, allowing the use of different cooling strategies. The reason for which it is necessary to have high flexibility in secondary cooling stands is the varying temperature-ductility curves of different steel grades. Figure [13] and [14] show the charts for Boron-added and Nbadded grades. For the B-added grades some special considerations are necessary. As proven by metallurgical studies [6], [7] these steel grades show a so-called "remelting" phenomenon that can easily induce cracks at high temperature. Therefore, a "hard cooling" strategy was applied to these grades, giving good results in terms of quality as shown in Figures [15] and [16]. After this practice was implemented most of the plates rolled and not subjected to inspection or conditioning were free of defects. Two typical temperature profiles - one for "soft cooling" and the other for "hard cooling" - are shown in Figures [17] and [18].

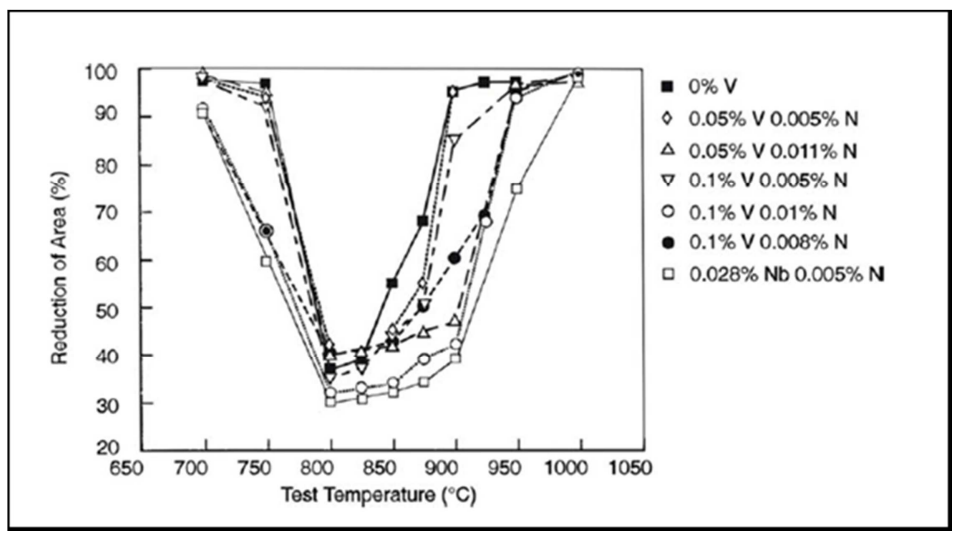

Figure 13: Hot ductility curve for $\mathrm{Nb}$-added grades

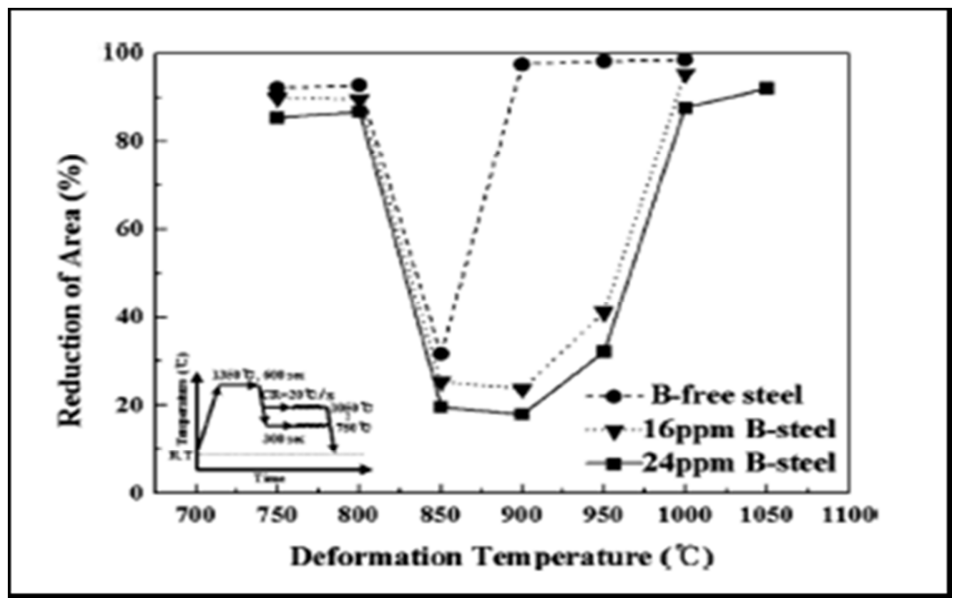

Figure 14: Hot ductility curve for B-added grades 


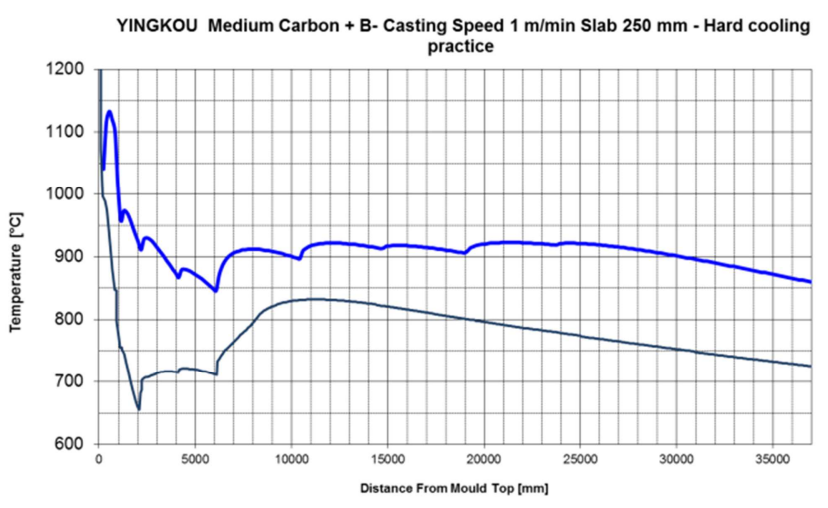

Figure 15: Temperature profile for slab centerline and corners when using hard cooling

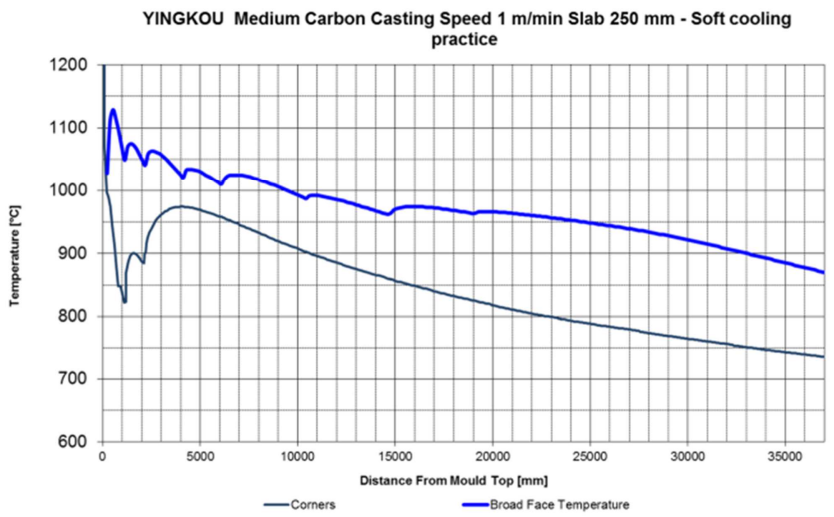

Figure 16: Temperature profile for slab centreline and corners when using soft cooling

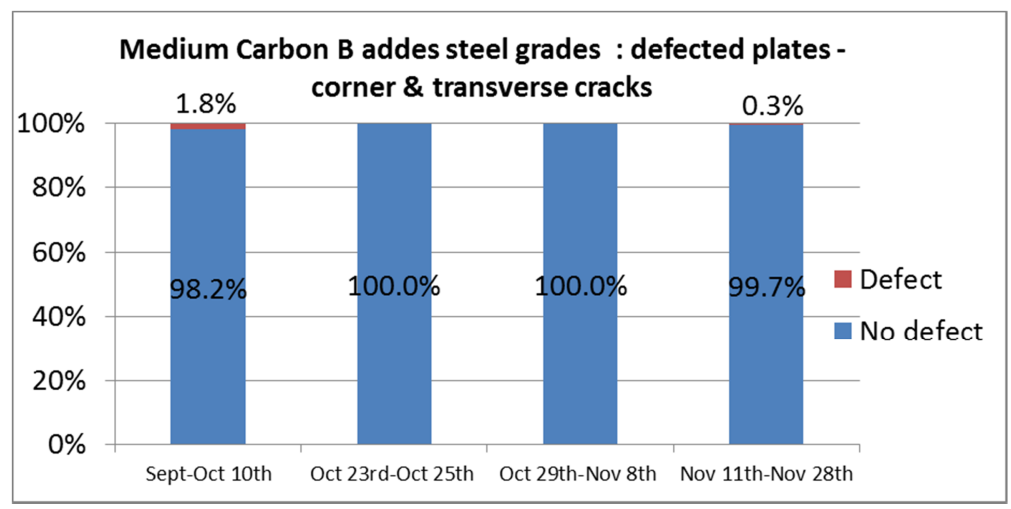

Figure 17: Plate surface quality

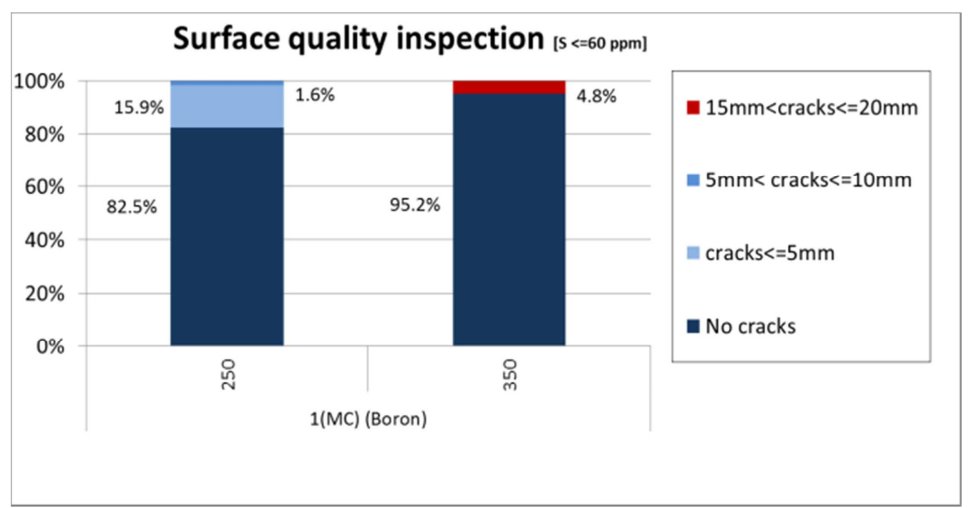

Figure 18: Hot test surface quality inspection 


\subsection{Internal Quality and Dimensional Tolerances}

To obtain good quality plates it is essential to guarantee the internal soundness of the slabs. The caster radius ensures a low strain to prevent cracks; and the softreduction machine is equipped with dynamic soft reduction to prevent centerline segregation.

\subsection{Dynamic Soft-Reduction Tuning}

What is important to make dynamic soft reduction effective is making sure it is applied at the right point. To do this it is necessary to determine where the liquid pool ends inside the strand. This is done using a program that calculates in real time the solidification profile, taking into account the main casting parameters. In order to be effective these models need to be properly set up as their reliability depends on the data input. Although heat transfer coefficient data are based on statistical data coming from experience, with a new caster a tuning may be necessary. The best way to do this is to determine where the liquid pool physically ends. For this purpose the Yingkou caster has been fitted with a recently developed tool called Q-Pulse. This system uses the equipment of the dynamic soft reduction system, and observes how mould level responds to a change in segment position. A small pulse is periodically given to a segment position (entry or exit) and the response of mould level to that frequency is recorded through FFT analysis. If the two frequencies match, it means that the segment position has not solidified yet. Thanks to this device, the soft reduction position was fine-tuned for all steel grades cast.

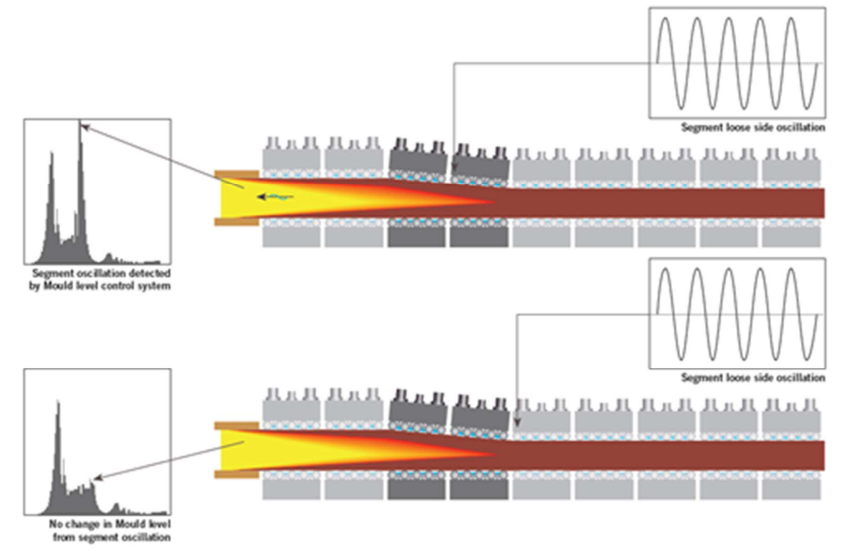

Figure 19: Q-Pulse working principle

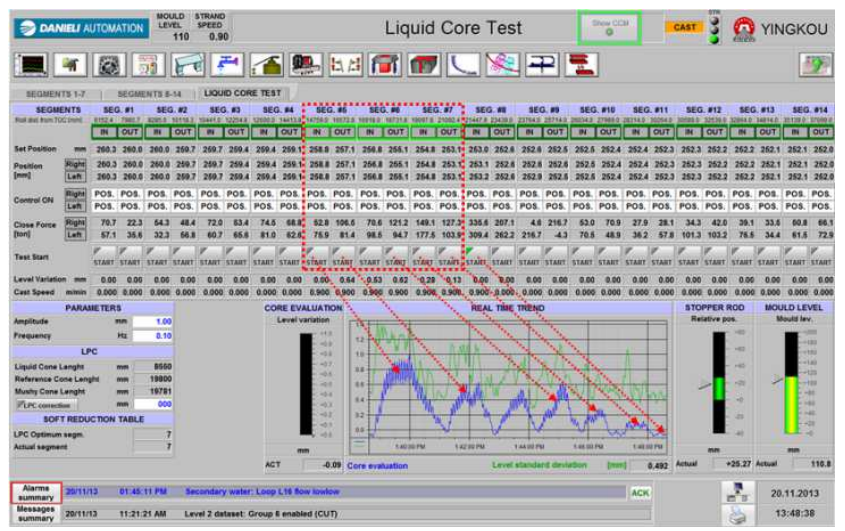

Figure 20: Q-Pulse interface 


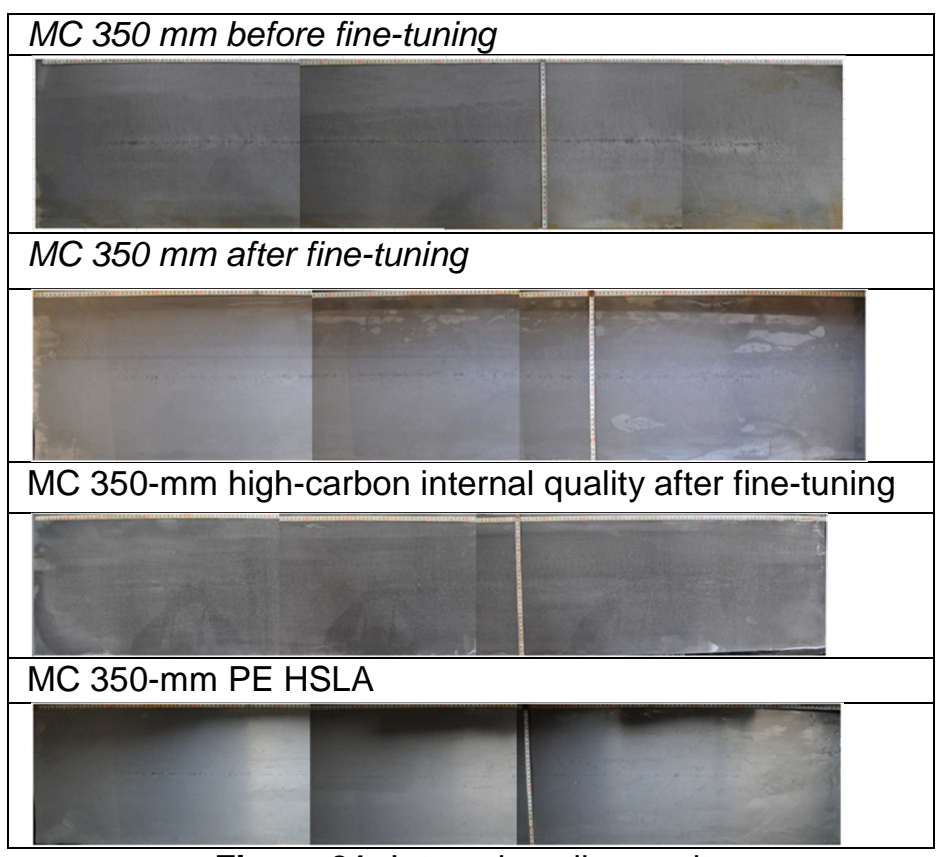

Figure 21: Internal quality results

\subsubsection{Narrow face shape}

One of the typical problems of very thick slabs is the bulging of the narrow face, with special attention paid to the design of the narrow face support and fine-tuning of taper and secondary cooling. This has resulted in slabs free of gutters on the broad faces and very limited bulging on the narrow faces.

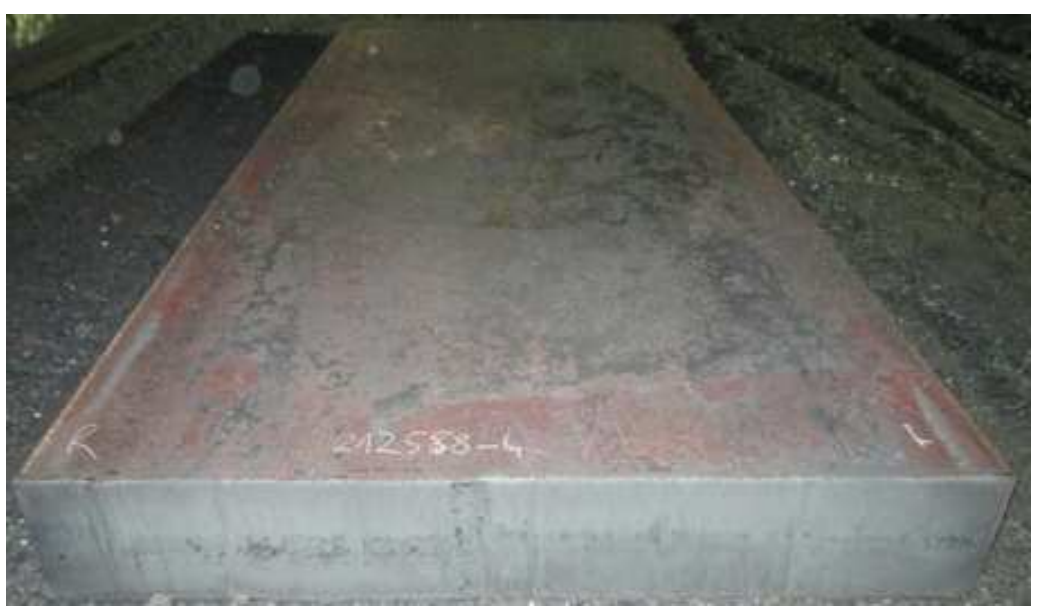

Figure 22: 350-mm-thick slab surface

\section{CONCLUSION}

To be competitive in the current steel market it is necessary to reliably cast highquality products. This task is particularly challenging when casting plate grades. For this reason all design aspects have been carefully taken into consideration, using the latest tools and solutions. Good design is a precondition, but only through accurate tuning of casting parameters is it possible to achieve the desired quality targets.

The technological packages are fundamental aids, firstly in the tuning process, and later during normal production they guarantee consistent results. 


\section{REFERENCES}

1 Pierre H. Dauby, "Continuous casting: make more steel and better of it!" Revue de Metallurgie 109, 113-116 (2012)

2 B. Rietow, B.G. Thomas "Using nail board experiments to quantify surface velocity in CC mould", AISTech 2008,Pittsburg, PA, May 5-8,2008

3 N. Triolet, K. Poelmans, P. Mabelly, Y. Le Papillon, "Prevention of corner cracks in slab continuous casting", Revue de Métallurgie / Volume 106 / Issue 11 / November 2009

4 B. Mintz, "The influence of composition on the hot ductility of steel and to the problem of transverse cracking", ISIJ International, Vol 39 ( 1999), N 9

5 D. N. Crowther, "The Effects of Microalloying Elements on Cracking During Continuous Casting" Corus Group, Swinden Technology Centre, Moorgate.

6 Hongbin Yin, Kenneth Blazek,Oscar Lanzi, "In situ Remelting Phenomenon after solidification of Fe-B alloy and B-bearing commercial steel", ISIJ International, Vol. 49 (2009), No 10

7 Kyung Chul CHO, Dong Jun MUN, Myeong Hun KANG, Jae Sang LEE,Joong Kil PARK,Yang Mo KOO2, "Effect of Thermal Cycle and Nitrogen Content on the Hot Ductility of Boron-bearing Steel, ISIJ International", Vol. 50 (2010), N6 